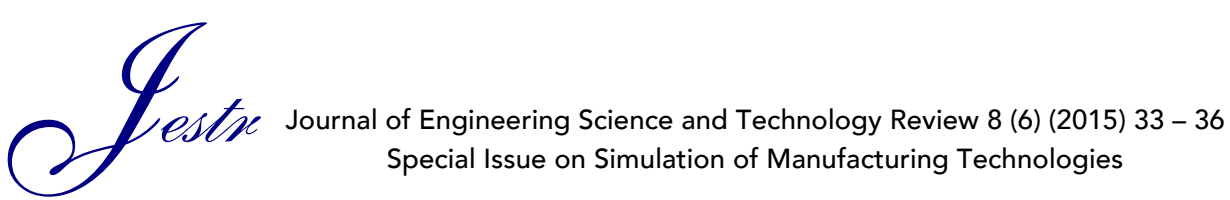

JOURNAL OF

Engineering Science and

Technology Review

Conference Article

\title{
Features of Microstructural Changes of an Aluminum Alloy D16T Samples Welded with Linear Friction Welding
}

\author{
Kiseleva S.K., Abramova M.M., Sitdikov V.D., Bychkov V.M., Medvedev A.Y., Musin F.F. and \\ Alexandrov I.V.
}

Ufa State Aviation Technical University, Ufa, Russian Federation

Received 4 September 2015; Accepted 8 September 2015

\begin{abstract}
The microstructure and microhardness of joint welds formed with linear friction welding (LFW) of an $\mathrm{Al}-\mathrm{Cu}-\mathrm{Mg}$ alloy was investigated. Welds of two samples of rectangular shape do not show any macroscopic defects and are characterized by high strength. The substantial transformation of the microstructure occurs in the weld. The lattice parameter decreases in the weld centre compared to the base material.
\end{abstract}

Keywords: aluminum alloy, linear friction welding, microstructure.

\section{Introduction}

Nowadays there are a few technological processes, allowing to form a metal junction without melting the weld line. They involve such different types of friction welding as: the rotational one, the orbital one and the linear one. The linear friction welding (LFW) is the advanced technology from the point of view of its application in aviation engineering for getting blisks. In connection with this there is growing interest in the last few years towards the LFW process of heat-resistant Ti alloys and steels [1-4].

Linear friction welding of Al alloys is also the subject of great interest from the point of view of applying this technology in production of blisks. However, in spite of a number of papers on the application of LFW [5] and its modeling [6,7], there is no any investigation in literature on the microstructure and microhardness of weld lines obtained with LFW of Al alloys.

Therefore, the aim of this work is to investigate the effect of LFW on microstructure and microhardness of aluminum alloy D16T.

\section{Experimental}

The deformable aluminum alloy D16T has been chosen as the material of investigation. The chemical composition of the alloy is given in Tab. 1. The samples heat treated at the $\mathrm{T} 2$ condition (heating at $500{ }^{\circ} \mathrm{C}$, water quenching and natural aging at room temperature).

The initial samples have been in form of parallelepipeds with length $40 \mathrm{~mm}$ and cross section $13 \times 26 \mathrm{~mm}$. The main welding parameters have been selected considering the LFW machine capabilities. Neither mechanical nor chemical

* E-mail address: nurieva_s@mail.ru ISSN: 1791-2377 @ 2015 Kavala Institute of Technology. All rights reserved. treatment of metal surfaces was used before welding. No post-weld heat treatment was carried out.

Table 1. Chemical composition (wt\%) of parent metal (D16T)

\begin{tabular}{c|c|c|c|c|c|c|c|c}
\hline $\mathbf{C u}$ & $\mathbf{M g}$ & $\mathbf{M n}$ & $\mathbf{S i}$ & $\mathbf{F e}$ & $\mathbf{C r}$ & $\mathbf{Z n}$ & $\mathbf{T i}$ & $\mathbf{A l}$ \\
\hline 4.11 & 1.55 & 0.72 & 0.21 & 0.24 & 0.03 & 0.25 & 0.15 & Bal. \\
\hline
\end{tabular}

Samples for microstructural investigations were prepared in the central zone of the welded sample. The metallographic samples were mechanically polished and chemically etched. The microstructural investigations were carried out in an optical microscope (OM) «OLYMPUS GX-51».

Electron-microscopic investigations of the structure were conducted using a transmission electron microscope «JEM100B». Objects for TEM have been prepared by jet polishing with a Tenupol-3 at a temperature of $-28^{\circ} \mathrm{C}$ and a voltage of $20 \mathrm{~V}$ in a $20 \%$ solution of nitric acid in methyl alcohol.

The X-ray diffraction (XRD) analysis was performed on a difractometer DRON 4-07 employing $\mathrm{Cu} \mathrm{K \alpha}$ radiation at $40 \mathrm{kV}$ and $30 \mathrm{~mA}$. The parameters of the crystal structure (lattice parameter a of the alloy, microdistortions of the crystal lattice $\left(\left\langle\varepsilon^{2}\right\rangle^{1 / 2}\right)$ and dislocation density) were determined by the method of full-profile analysis of diffraction patterns using the program MAUD.

Vickers hardness measurements were taken with a hardness-testing machine «Struers Duramin» with a $1 \mathrm{~N}$ load across the joints at a distance of $0.5 \mathrm{~mm}$ apart.

\section{Results}

At a macroscopic visual inspection, linear friction joints were characterized by the presence of plastically deformed flash material, extruded along the short and long sides of the sample section, as shown in Fig.1. 


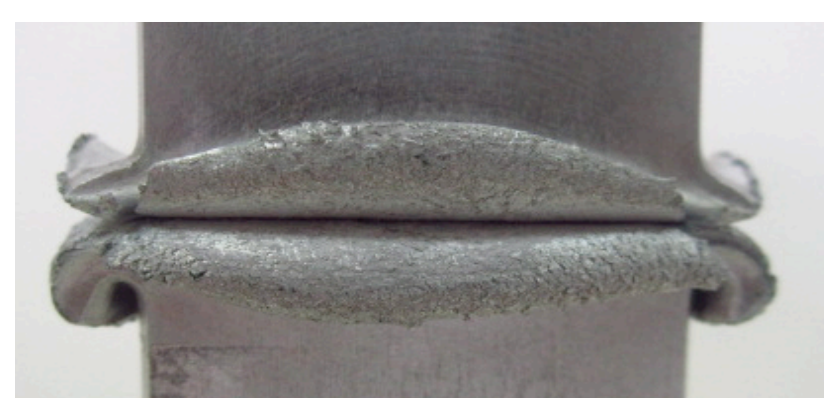

Fig 1. Side view of a linear friction welded joint

The microstructural analysis did not identify any of the typical defects found in fusion welded Al-alloy, such as particle segregation, gas pores, discontinuities, fusions. The microstructure of the samples after welding in the contact zone of the two materials can be divided into three zones: 1 - Weld Centre; 2 - Thermo-Mechanically Affected Zone (TMAZ); 3 - Base Material (Fig. 2). These zones vary in etching, grain size and shape.

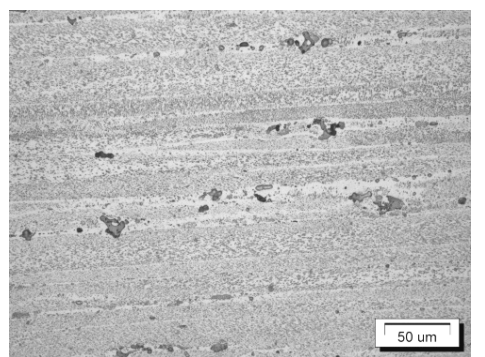

(a)

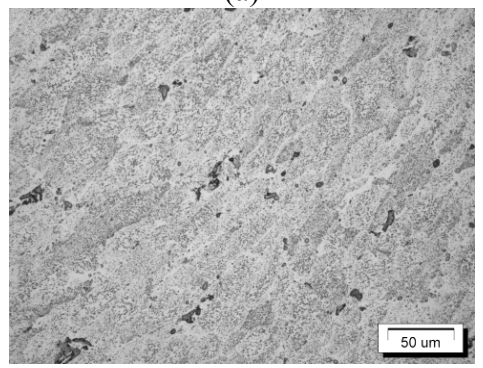

(b)

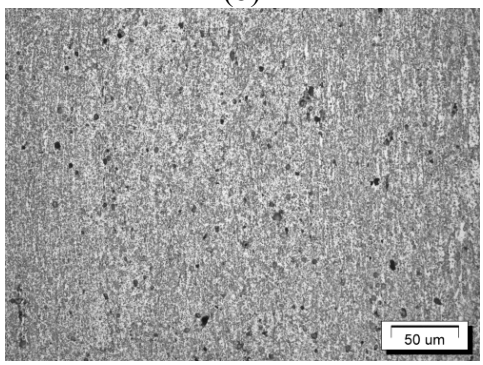

(c)

Fig. 2. Microstructure D16T after linear friction welding, (a) base material, (b) TMAZ, (c) weld centre (optical microscope)

The base material (Fig. 2a) is characterized by a pronounced metallographic texture inherited from the parent material after pressing. Thus grains on both sides of the weld are oriented perpendicularly. The grain boundaries are substantially rectilinear in shape, while in certain places there are undulation boundaries. Stroke precipitations of non-equilibrium phase are observed along the boundary of elongated grains. The volume fraction of non-equilibrium phase is $15.0 \pm 0.5 \%$.

Rotation of the initial elongated grains in a direction parallel to the plane of the connection is observed in the Thermo-Mechanically Affected Zone (Fig. 2b). The presence of such a structure shows significant plastic deformation of the material. Furthermore, the emergence of equiaxed grains appeared in this field. The average grain size is $5.0 \pm 0.5$ $\mathrm{mm}$. The appearance of equiaxed grains in this area appears to be associated with recrystallization.

The weld centre differs from the rest of the specimen as it is most difficult to etch (Fig. 2c). The grain boundaries cannot be detected in this zone. In the weld centre relevant grain refinement occurred, due to the concurrent effect of frictional heating and severe plastic deformation caused by the solid state welding process. There are no nonequilibrium phases, which were observed in the base material and in the TMAZ.

Electron-microscopic analysis of structure showed two types of intermetallic particles (Fig. 3). The first type of particles has the form of a needle (area 1), located on the grain boundary and in the body of the grains. This type of particles is observed both in the base material and the weld centre. According to [8-10] needle type particles refer to Mn-intermetallic compound (Al-Cu-Mn-phase), which is dispersed in the form of solid solution in the homogenization process.

The second type of particles (area 2) has a rod-like shape. The average size of allocations is less than $10 \mathrm{~nm}$. Particles are placed in a grid, reminiscent of basket weaving. Particles of this type are phases emitted from the solid solution during aging [8-10]. This may be the CuAl2 and $\mathrm{Al}_{2} \mathrm{CuMg}$ phase.

The line zone is also characterized by the increased density of dislocations. Grain boundaries are straight. The average grain size is $1 \mu \mathrm{m}$.

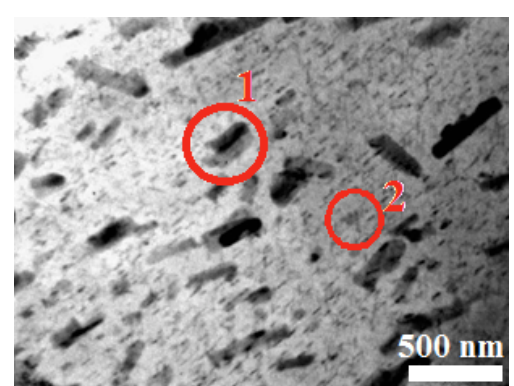

(a)

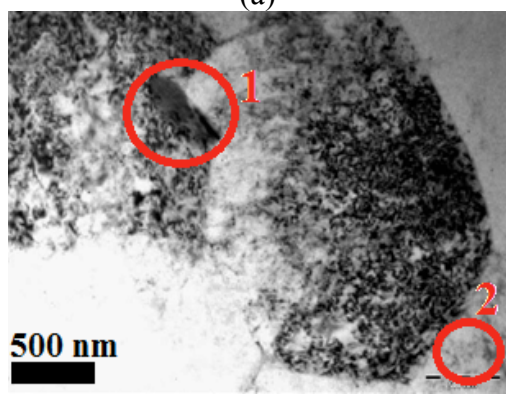

(b)

Fig.3 Microstructure of D16T alloy after linear friction welding, (a) base material, (b) weld centre; TEM

Microhardness measurements across the weld are shown in Fig. 4. On either side of the weld, in the TMAZ the drop 
in microhardness by approximately $15 \mathrm{HV}$ is observed with respect to the base material.

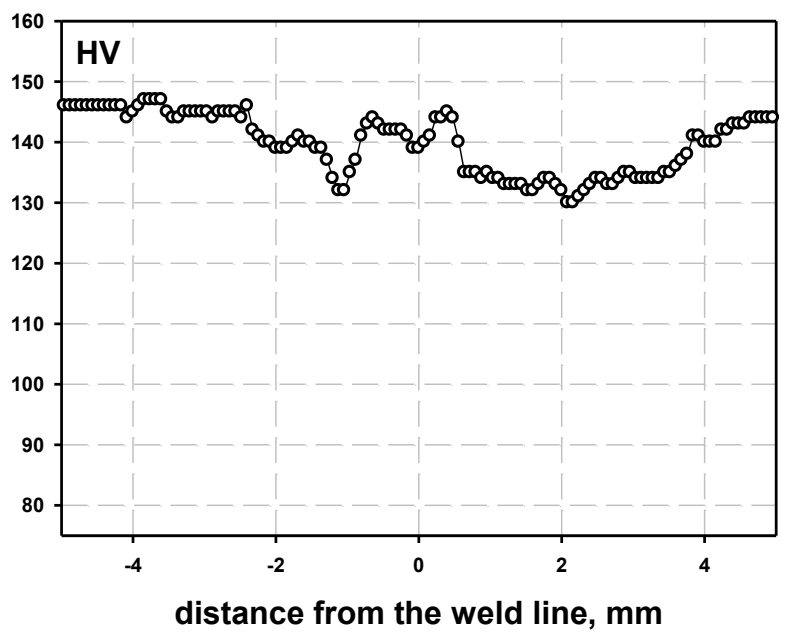

Fig. 4. The microhardness distribution in the sample after linear friction welding

The XRD results are listed in Table 2. It is seen that linear friction welding is accompanied by a decrease of the lattice parameter $a$ of solid solution in the weld centre. The maximum dislocation density $\rho$ is obtained in the weld centre too.

Table 2. Microstructural characteristics of the alloy D16T determined by the XRD method

\begin{tabular}{l|c|c|c}
\hline & $\boldsymbol{a}, \mathbf{A}$ & $\left\langle\boldsymbol{\varepsilon}^{2}\right\rangle^{\mathbf{1 / 2}}, \mathbf{\%}$ & $\boldsymbol{\rho}, \mathbf{m}^{-\mathbf{2}}$ \\
\hline $\begin{array}{l}\text { D16T, base } \\
\text { material }\end{array}$ & $4.0510 \pm 0.0004$ & $0.038 \pm 0.007$ & $\sim 3.6$ \\
$\begin{array}{l}\text { D16T, welding } \\
\text { centre }\end{array}$ & $4.0507 \pm 0.0001$ & $0.062 \pm 0.11$ & $\sim 6.1$ \\
\hline
\end{tabular}

\section{Discussion}

The results of the present investigations have shown that a defect-free weld was formed with LFW with samples of aluminum alloy D16T. The microhardness is distributed heterogeneously across the weld, which may be related to the circumstances of microstructural changes.

While parts rubbed against each there is significant heating in a narrow contact area of the ingot material. When the whole process of LFW was completed the narrow nearcontact zone of the weld centre was quenched in air, which obviously leads to the formation of a supersaturated solid solution at room temperature. The process of natural aging begins under subsequent aging in the material.

The classic precipitations sequence appearance in the Al$\mathrm{Cu}-\mathrm{Mg}$ - alloy system with the rising of duration or temperature aging is as following [8].

$$
\mathrm{SSS} \rightarrow \text { GPB zone } \rightarrow \mathrm{S}^{\prime \prime} \rightarrow \mathrm{S}^{\prime} \rightarrow \mathrm{S}\left(\mathrm{Al}_{2} \mathrm{CuMg}\right)
$$

where SSS - supersaturated solid solution; GPB Guineer-Preston-Bagaryatsky.

The authors of [11] proposed another precipitation sequence:

$$
\begin{gathered}
\text { SSS } \rightarrow \text { Cu-Mg co-clusters } \rightarrow \\
\text { GPB2/S" } \\
\rightarrow \text { orthorhombic }) \rightarrow \text { S ( }\left(\mathrm{Al}_{2} \mathrm{CuMg}\right) .
\end{gathered}
$$

$\mathrm{Cu}-\mathrm{Mg}$ co-clusters appear during initial natural aging. Under subsequent artificial aging they are dissolved and replaced by $\mathrm{S}\left(\mathrm{Al}_{2} \mathrm{CuMg}\right)$ precipitates, that coarsen after longer time exposure at high temperature.

Based on present data and literature analysis [12], we can introduce the following model of microstructural changes in the weld zone.

In the initial state, the samples were subjected to quenching and natural aging. Under heating the growth process of hardening particles, and in particular the S-phase could begin in the TMAZ. As a result, microhardness in this zone is decreased compared to the base material.

The heating in the weld centre could lead to the dissolution of $\mathrm{Cu}-\mathrm{Mg}$ co-clusters and $\mathrm{S}$ - phase. As a result of rapid cooling and subsequent natural aging formation of new $\mathrm{Cu}-\mathrm{Mg}$ - clusters begins. The results of the X-ray analysis showed that the lattice parameter decreased in the weld centre. This could be associated with the formation of $\mathrm{Cu}-\mathrm{Mg}$ - clusters from solid solution. However, the material of the sample before welding was subjected to quenching and natural aging and, consequently, differences in the lattice parameter for the weld centre and the base material should not appear.

Linear friction welding is the process related to the temperature effect and to the plastic deformation influence.

Our research has shown that the weld centre is characterized by significant grain refinement to the ultra-fine grain (UFG) condition (Fig.3b) while dislocation density increases. Possibly, the decrease of lattice parameter in the weld centre is associated with the occurrence of compressive stress fields created by the ultra-fine grains boundaries. The similar phenomenon is observed for materials after severe plastic deformation (SPD), in particular for pure aluminum [13].

\section{Conclusions}

1. It has been established that significant microstructure transformation takes place in the welding zone during the plastic deformation and deformation heating-up.

2. It has been shown that microhardness is distributed heterogeneously across the welding zone. The microhardness reduce is observed in the TMAZ.

3. The lattice parameter decreases in the weld centre compared to the base material.

4) The present results can be useful to describe an adequate model of the LST process of aluminum alloys.

\section{Acknowledgments}

This work was performed with financial support from The Ministry of Education and Science of the Russian Federation within the framework of the design part of the state task №11.2540.2014/K educational organization of higher education 


\section{References}

[1]. W.-Y. Li, T.J. Ma, S.Q. Yang, Q.Z. Xu, Y. Zhang, J.L. Li, H.L. Liao, "Effect of friction time on flash shape and axial shortening of linear friction welded 45 steel", Materials Letters, vol.62, p.293-296, 2008.

[2]. Zakirova A. A., Ngimov M. I., Khusnullin A. M., Kashaev R. M. "Structure, properties and hot deformation of a welded joint of steel $08 \mathrm{KH} 18 \mathrm{~N} 10 \mathrm{~T}$, obtained by linear friction welding (LST)", Advanced materials, p. 155-159, 2011. [in Russian]

[3]. M. Karadge, M. Preuss, C. Lovell, P.J. Withers, S. Bray "Texture development in Ti-6Al-4V linear friction welds", Materials Science and Engineering, A 459, p.182-191, 2007.

[4]. Karavaeva M. V., Kiseleva S. K., Bychkov V., Medvedev, A. Y., Soups, A. V., Musin, F. F., Alexandrov I. V., Latysh V. V. "Influence of the magnitude of precipitation on the formation of the welded joint during the linear friction welding", Letters on materials, vol. 2, p.40-44, 2012. [in Russian]

[5]. [5]. Livan Fratini, Gianluca Buffa, Marco Cammalleri, Davide Campanella "On the linear friction welding process of aluminum alloys: Experimental insights through process monitoring", Manufacturing Technology, vol.62, p.295-298, 2013.

[6]. X. Song,M. Xie, F. Hofmann, T.S. Jun, T. Connolley, C. Reinhard, R.C. Atwood, L. Connor, M. Drakopoulos, S. Harding, A.M. Korsunsky "Residual stresses in Linear Friction Welding of aluminium alloys", Materials and Design, vol.50, p.360-369, 2013.

[7]. Li Qinghua, Li Fuguo, Li Miaoquan, Wan Qiong, and Fu Li "Finite Element Simulation of Deformation Behavior in Friction Welding of Al-Cu-Mg Alloy", JMEPEG, vol.15, p.627-631, 2006

[8]. Theory of heat treatment: a Textbook for high schools. 4-e Izd., Rev. and add: I. I. Novikov: Metallurgy, 1986. [in Russian]

[9]. Aluminum: properties and physical metallurgy: Ref, ed. TRANS. angl. /Edited by J. Hatch. E. M.: Metallurgy, 1989. [in Russian]

[10]. Bochvar A. A. Metallography. M: Metallurgizdat 1945. [in Russian]

[11]. Wang S.C., Starink M.J. "Precipitates and intermetallic phases precipitation hardening Al-Cu-Mg-(Li) based alloys", International Materials Review, vol. 50, no.4, p.193-215, 2005.

[12]. Rotundo F., Ceschini L., Morri A., Jun T.-S., Korsunsky A.M. "Mechanical and microstructural characterization of $2124 \mathrm{Al} / 25$ vol.\%SiCp joints obtained by linear friction welding (LFW)", Composites: Part A, vol.41, p.1028-1037, 2010.

[13]. Valiev R.Z., Alexandrov I.V., Bulk Nanostructured Metallic Materials. «Akademkniga», Moscow, 2007. [in Russian] 